\title{
Planar Patch Antenna for 2.4 GHZ Wireless Applications
}

\author{
${ }^{1}$ B. Shashi Kranth,${ }^{2}$ G.Krishna Dilip, ${ }^{3}$ K. Bhagath Kumar \\ ${ }^{1,2}$ Dept. of Electronics \& Communication Engineering ACE Engineering College Ghatkesar, A.P, India. \\ ${ }^{3}$ Guide:Chandu DS,Assistant Professor Dept. of Electronics \& Communication Engineering \\ ACE Engineering College Ghatkesar, A.P, India.
}

\begin{abstract}
This paper presents the theory and design of a planar patch antenna in the shape of a rectangle at 2.4GHz. The antenna is designed with FR4 as a substrate which has a dielectric constant of 4.4. The frequency of operation is chosen to be $2.4 \mathrm{GHz}$ as the antenna can support many wireless applications in the frequency band like Wi-Fi and Bluetooth. The antenna is simulated using Ansoft's High Frequency Structure Simulator. The designed patch antenna has a return loss of $-24 d B$ which is acceptable given the scope of the antenna.

Index Term: FR4, Microstrip, Return Loss, Substrate
\end{abstract}

\section{Introduction}

With The Ever-Increasing Need For Mobile Communication And The Emergence Of Many Systems, It Is Important To Design Broadband Antennas To Cover A Wide Frequency Range.[1] The Design Of An Efficient Wide Band Small Size Antenna, For Recent Wireless Applications, Is A Major Challenge. A Patch Antenna Has 4 Slots, 2 Of Which Are Non -Radiating. Microstrip Patch Antennas Have Found Extensive Application In Wireless Communication System Owing To Their Advantages Such As Low- Profile, Conformability, Low-Cost Fabrication And Ease Of Integration With Feed Networks. [2]However, Conventional Microstrip Patch Antenna Suffers From Very Narrow Bandwidth, Typically About 5\% Bandwidth With Respect To The Centre Frequency. In This Paper, A Computer Aided Design Of A High Frequency Rectangular Antenna Is Proposed Using EM Modeling Technique And Choosing The Best Results To Develop The Hardware Of The Antenna That Makes It An Accurate And Reliable System For Commercial Wireless Applications.

[3] The Transmission Line Model Of Patch Antenna Is Used In This Paper To Obtain The Mathematical Equations And The Dimensions Of The Patch Antenna. All The Materials That Are Metals Are Chosen To Be Copper.[4] The Substrate FR4 Is Widely Used In Commercial Printed Circuit Boards And Has Become The Choice Of The Design. The Substrate Is Widely Available, Cheap But Not Flexible. The Simulator Can Model High Frequency Structure Particularly Of The Passive Devices In The Microwave Regions. The Simulator Belongs To The Finite Element Class And This Method Of Designing The Antenna Can Be Termed As Finite Element Design. The Antenna Is A Given A Co-Axial Probe Feed.

\section{Antenna Design}

The Basic Structure Of The Proposed Antenna, Shown In Fig. 1, Consists Of 3 Layers. The Lower Layer, Which Constitutes The Ground Plane, Covers The Partial Rectangular Shaped Substrate With A Side Of $33 \times 38 \mathrm{Mm}$. The Middle Substrate, Which Is Made Of FR4 Epoxy Resin, Has A Relative Dielectric Constant Gr=4.4 And Height 3.2 Mm. The Upper Layer, Which Is The Patch, Covers The Rectangular Top Surface. The Rectangular Patch Has Sides 33×38 Mm That Covers The Middle Portion Of The Substrate. Two Rectangular Slots Are Cut Out From The Patch Near The Feeding Microstrip Line For Impedance Matching. The Patch Is Fed By A Microstrip Line With $50 \Omega$ Input Impedance.

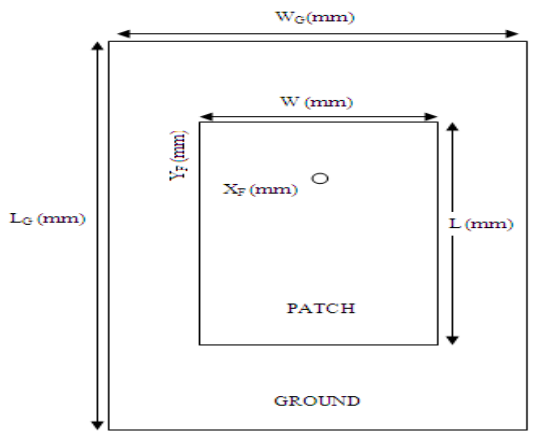

Fig.1. Schematic of the Rectangular Patch Antenna 
The Antenna Is Designed To Operate In The 2-2.4ghz Band With A Center Frequency Of 2.2ghz To Meet The Wireless Specifications. The Substrate Of The Antenna Is Chosen To Be Flame Redundant FR4 With A Dielectric Constant (Er) Of 4.4 With 3.2mm Thickness And The Ground Plane Made Of Copper Is Located On The Other Side Of The Substrate. The Antenna Is Fed By A Standard Strip Of $50 \Omega$ And This Type Of Feeding Is To Be Placed At The Point On The Patch So As To Match With The Desired Input Impedance And Reduce Spurious Radiations.

The Width (W) Of The Patch Antenna Can Be Determined By [2] :

$$
W=\frac{v}{2 f(\sqrt{(2(a r+1) / 2)}}
$$

The Effective Dielectric Constant Is Defined Before Calculating The Length Of The Antenna:

$$
\text { Ereff }=\frac{a r+1}{2}+\frac{a r-1}{2}\left[1+\frac{12 k}{w}\right]^{-0.5}
$$

H, Here Is The Height Of The Substrate And W Is The Value As Obtained In (1). The Dimensions Of The Patch Along Its Length Have Been Extended On Each End By A Distance Of $\Delta \mathrm{L}$ Which Is Given Empirically By:

$$
\Delta L=\frac{0.412 h(\text { sreff }+0.3)\left(\frac{w}{n}+0.264\right)}{(\text { sreff }-0.258)\left(\frac{w}{h}+0.8\right)}
$$

The Actual Length L Of The Patch Is Given By:

$$
L=\frac{\lambda}{2}-\Delta L
$$

$\Lambda 0$ In (4) Is The Free Space Wavelength At Center Frequency. The Ground Plane Dimensions Are Greater Than The Patch Dimensions By Approximately Six Times And Are Given As:

$$
\begin{aligned}
& \mathrm{LG}=6 \mathrm{~h}+\mathrm{L} \\
& \mathrm{WG}=6 \mathrm{~h}+\mathrm{W}
\end{aligned}
$$

The Co-Ordinates For The Position Of The Coaxial Feed Point Can Be Obtained By Using:

$$
\begin{gathered}
\mathrm{X}_{F}=\frac{\mathrm{L}}{\sqrt{\varepsilon_{\text {reff }}}} \\
\mathrm{Y}_{F}=\frac{\mathrm{W}}{2}
\end{gathered}
$$

The Following Table Summarizes The Antenna Parameters On Substituting The Design Values Through (1) -

\section{Simulation Of The Antenna}

The Basis Of The Simulation Technique Is To Have A Discrete View Of The Problem Region By Dividing The Design Into Finite Number Of Elements. Each Such Element Is To Be Modelled Individually. The Entire Volume Of The Patch Antenna Is Meshed And Each Mesh Will Have Different Material Properties Than Its Neighbourhood. This Is Called Volume Meshing. The Simulator Tool Used For The Design Is High Frequency Structure Simulator (HFSS). Major Steps In Building The Antenna Using HFSS -

(I) Create Rectangles With The Dimensions As Shown In Table I For Designing The Substrate, Ground And The Patch. 
(Ii) Create Two Cylinders, Subtract Them And Join The Resultant To A Circle Of Radius 3.2mm To Construct A Coaxial Cable.

(Iii) Excite The Antenna Via The Feed By Assigning A Wave Port.

(Iv) Select The Solution Type To Be A Driven Terminal And Analyse The Antenna For A Solution Frequency Of 2.4ghz.

The Antenna Developed Is As Shown In Fig.2 And The Corresponding Results Are Displayed In The Next Section.

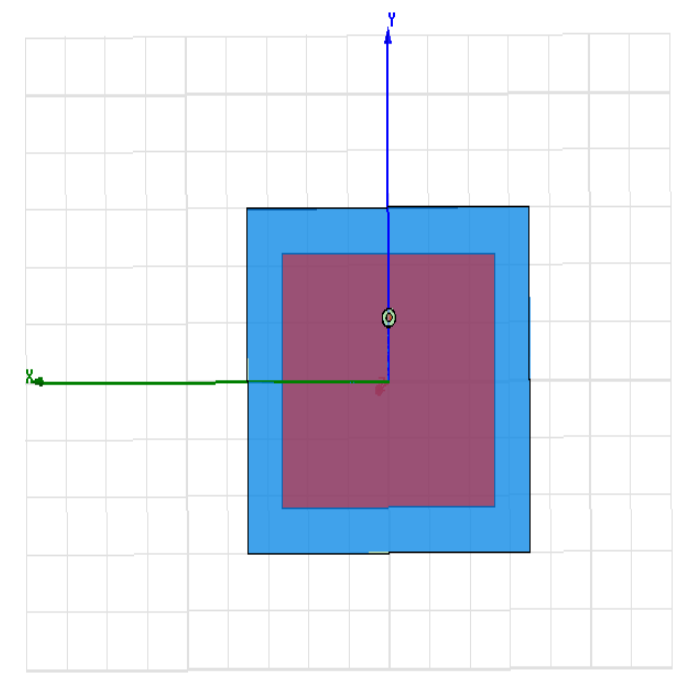

Fig.2. Patch Antenna Designed In HFSS

Table I Antenna Dimensions

\begin{tabular}{|c|c|}
\hline L & $33.1676 \mathrm{Mm}$ \\
\hline W & $38.7046 \mathrm{Mm}$ \\
\hline LG & $53.7 \mathrm{Mm}$ \\
\hline WG & $63 \mathrm{Mm}$ \\
\hline XF & $\mathrm{Mm}$ \\
\hline YF & $10.8 \mathrm{~mm}$ \\
\hline
\end{tabular}

IV. Results

The Results Obtained Upon Simulating The Antenna Is Presented In This Section. The Impedance And Radiation Characteristics Of The Antenna Are Observed And Analysed. Fig.3, Fig.4 And Fig.5 Are The Results Obtained Using HFSS Tool. The Return Loss Of The Antenna At Center Frequency Is Around $-22 \mathrm{Db}$. This Corresponds To A VSWR Of Nearly 1.13:1 Which A Very Good Response Is Given The Specification And Application Of The Antenna. A Voltage Standing Wave Ratio Of Less Than 2 (VSWR<2) Is Always Acceptable.

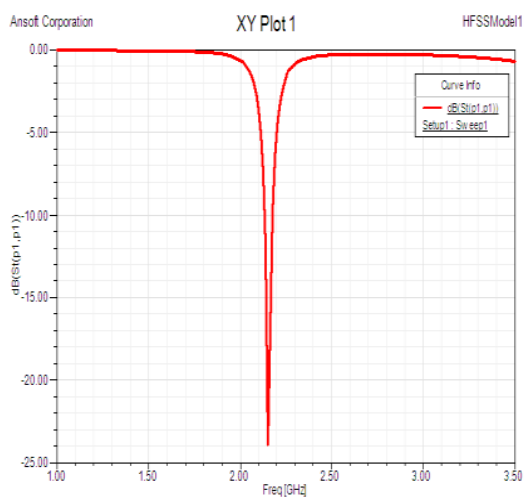

Fig.3. Return Loss of The Antenna In HFSS (-22db) 


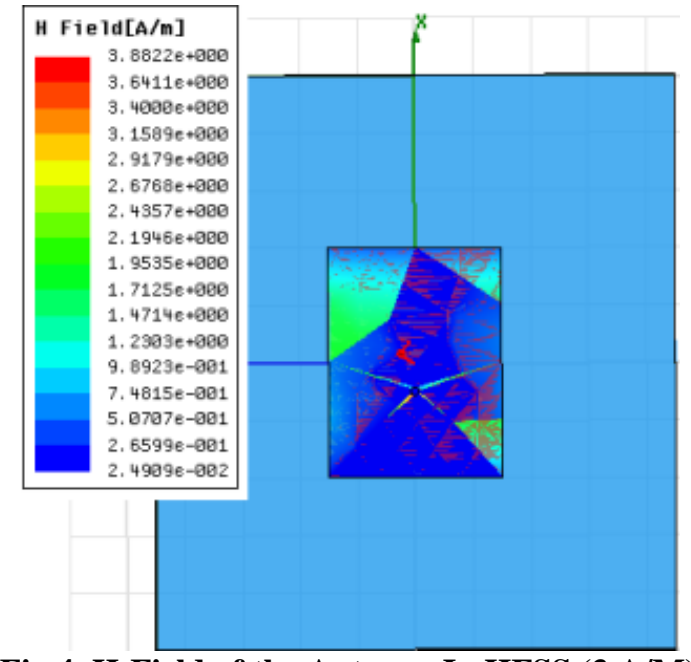

Fig.4. H-Field of the Antenna In HFSS (3 A/M)

This Implies That The Maximum H-Field Lies Along The Outer Edges Of The Patch And Are Supposed To Be Radiating Edges. The Non Radiating Edges On The Opposite Side Do Not Carry Any Current And Filed There Is Always Zero. The Directive Gain Of The Antenna Is Found To Be 2db.

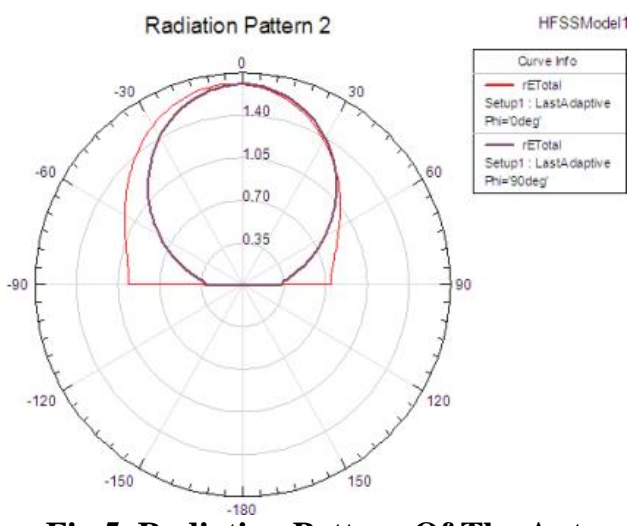

Fig.5. Radiation Pattern Of The Antenna

\section{Conclusion}

The Design Of The Antenna Starting From The Theoretical Aspects Was Presented And The Results Are Observed To Be Satisfactory For A Product At 2.4ghz. However, The Antenna Has To Be Developed Accordingly So As To Meet The Challenges And Combat With Fading And Path Loss Parameters Of The Wireless Mobile Environment. The Results Obtained From The Simulator Show That The Antenna Radiates Back Less Than 20\% Of The Transmitted Power With A Directive Gain Of 2dbi And At A Maximum Field Of 3 A/M From Its Edges.

\section{References}

[1]. Chandu DS, Ramesh Deshpande, "Computational Analysis of $2.25 \mathrm{GHz}$ Rectangular Patch Antenna", International Journal of Engineering Research and Technology, vol.2., page 1-8, October,2012.

[2]. Balanis C.A. (2005) Antenna Theory: Analysis and Design, John Wiley \& Sons.

[3]. C. Wu, K. Wu, Z. Bi and J. Litva, "Accurate Characterization of Planar Printed Antennas using Finite - Difference Time - Domain method, "IEEE Transactions on Antennas and Propagation, vol. 40, May 1992.

[4]. M. Zweki, R. A. Abd - Alhameed, M. A. Mangoud, P. S. Excell, and J. A. Vaul, "Broadband Analysis of Finite Microstrip Patch Antenna Structure using FDTD ", 11th International Conference on Antennas and Propagation, UMIST, Manchester, UK, April 2001. 